\title{
Nutritional Composition of Telfairia occidentalis Leaf Grown in Hydroponic and Geoponic Media
}

\author{
*OKONWU, K; AKONYE, LA; MENSAH, SI \\ Department of Plant Science and Biotechnology, University of Port Harcourt, \\ P.M.B. 5323, Port Harcourt, Nigeria. \\ *Corresponding author Email: kalu.okonwu@uniport.edu.ng
}

\begin{abstract}
The bioactive components of Telfairia occidentalis Hook F. leaf grown in both geoponic (GM) and non-circulating hydroponic (HM) media were assessed. The bioactive components assessed were vitamins, proximate composition and amino acids. Standard procedures were followed in the analyses. The percentage vitamins showed that cobalamin content was the highest $(40.29 \%)$, followed by beta-carotene $(19.89 \%)$, riboflavin $(13.25 \%)$, ascorbic acid $(10.33 \%)$, thiamine $(9.78 \%)$, pyridoxine $(6.13 \%)$, niacin $(3.46 \%)$, tocopherols $(2.66 \%)$ and Vitamin K $(1.46 \%)$ in that order for $\mathrm{HM}$ while the sequence for GM was beta-carotene $(17.27 \%)$, cobalamin $(12.70 \%)$, thiamine $(6.13 \%)$, ascorbic acid $(3.16 \%)$, pyridoxine $(2.12 \%)$, niacin $(1.25 \%)$, tocopherols $(0.97 \%)$, riboflavin $(0.80 \%)$ and Vitamin $\mathrm{K}(0.63 \%)$. The proximate composition of $T$. occidentalis varied in HM and GM. The percentage protein were $0.53 \%$ and $0.30 \%$, crude fat $(0.90 \%$ and $0.30 \%)$, moisture $(83.36 \%$ and $81.42 \%)$, crude fibre $(2.09 \%$ and $4.76 \%)$ and ash $(0.37 \%$ and $0.47 \%)$ for HM and GM, respectively. The carbohydrate composition $(12.76 \%)$ remained same for both treatments. The essential and non-essential amino acids ranges from $0.11-3.44 \%$ and $0.01-2.51 \%$ for $\mathrm{HM}$ and $0.05-1.73 \%$ and $0.01-1.26 \%$ for GM, in that order. The percentage total amino acids of $T$. occidentalis grown in HM and GM were $19.07 \%$ and $9.77 \%$, respectively. The study therefore support the growing of T. occidentalis in hydroponic nutrient medium with the aim of improving the bioactive components, directly providing the nutritional requirements of humans and thereby addressing an aspect of food security challenges.
\end{abstract}

DOI: https://dx.doi.org/10.4314/jasem.v22i2.18

Copyright: Copyright (C) 2018 Okonwu et al. This is an open access article distributed under the Creative Commons Attribution License (CCL), which permits unrestricted use, distribution, and reproduction in any medium, provided the original work is properly cited

Dates: First received 17 October 2017; Received in revised form 17 November 2017; Accepted .February 2018

KEY WORDS: Bioactive, geoponic, hydroponic, medium of growth

Natural foods are source of vitamins that are required by humans. It has been reported that vegetables contains numerous vitamins such as beta carotene, ascorbic acid, riboflavin, folic acid as well as minerals like iron, calcium, phosphorus and others (Gupta et al., 2008; Lubdha and Anjali, 2014). These vitamins and minerals are essential dietary constituents required for growth, development and reproduction. According to Funke (2011), the minerals in vegetables contribute to the alkaline substance in the body, which enables the body to maintain acid-base balance. The absence of any particular vitamin may result in a nutritional diseases which is characteristic of that specific vitamin. Vegetables act as powerful medicine which can help reduce the risk of chronic diseases (Gosslau and Chen, 2004; Lee et al., 2008). It has a great potential against heart diseases, cancer, blood pressure and high cholesterol (Antonious et al., 2009). Lawal et al. (2015) reported that fresh vegetables contain high amount of ascorbic acid content when compared to vegetables that have undergone any form of processing. Vegetable is highly perishable and require careful processing in order to preserve the nutrients, especially the water soluble vitamins.

Leafy vegetables are sources of essential and trace elements which play a major role in the normal functioning of the body system, maintaining regular metabolic processes and repair of worn-out cells and tissues in man (Bruijnzeel et al., 2010). The cooked leaves are staple vegetable in soups and stews of various cultures throughout equatorial Africa (Kokwaro, 2009; Egedigwe, 2010). Telfairia occidentalis is indigenous to southern Nigeria, and used primarily in soups and herbal medicine. In the light of advancement in vegetable production using various methods, the study therefore seek to determine and quantify the bioactive components of T. occidentalis grown in non-circulating hydroponic and geoponic medium.

\section{MATERIALS AND METHODS}

The seeds of $T$. occidentalis were obtained from a farm in Choba Port Harcourt, Nigeria. The seeds were divided into two batches and planted in white sand from the Choba River and top humus soil $(0-25 \mathrm{~cm})$ from a garden in University of Port Harcourt

*Corresponding author Email: kalu.okonwu@uniport.edu.ng 
respectively as a medium for germination. The two weeks old seedlings from the white sand were transferred into a non-circulating hydroponic nutrient system. The nutrient solution used for the hydroponic was bicfarmsconcept formulation. The plants in both hydroponic medium (HM) and geoponic medium (GM) were allowed to stand for a month, when it can be harvested to prepare food. The matured leaves were harvested and used to determine the vitamins, proximate composition and amino acids of $T$. occidentalis grown in both geoponic and hydroponic medium.

Proximate Analysis: Proximate analysis (moisture, ash, protein, carbohydrate and lipid content) was determined using standard method of AOAC. Fibre was determined by difference.

Determination of crude protein (Kjeldahl method): Plant samples weighing $0.1 \mathrm{~g}$ were put into different conical flasks, $3 \mathrm{~g}$ of digestion catalyst and $20 \mathrm{ml}$ of concentrated sulphuric acid was added into the flask. The flasks were then heated gently to boil in a fume chamber, until charred particles disappeared and clear greenish grey solution was obtained. The resulting solution in the conical flask was heated for an additional 20 minutes and allowed to cool. The digest was diluted with water to $100 \mathrm{ml}$ capacity and $20 \mathrm{ml}$ was then measured into a distillation flask and this was connected to a condenser adapted to a receiver beaker containing $10 \mathrm{ml}$ of $2 \%$ boric acid with 2 drops of double indicator. $\mathrm{NaOH}(40 \%)$ was added to the digest, the distillation flask was then heated to distil the nitrogen present as ammonia. The boric acid in the receiver was titrated with standard $0.1 \mathrm{~N}$ hydrochloric acid.

The volume of $\mathrm{HCl}$ used was recorded as titre value. The formula for the calculation of total Nitrogen is:

$$
\% \text { Nitrogen }=\frac{\text { Titre value } \times 1.4 \times 100}{1000 \times 20 \times 0.1}
$$

Where Titre value $=$ Volume of Hydrochloric acid used, $1.4=$ Nitrogen equivalent in relation to the normality of $\mathrm{HCl}$ used in titration, $100=$ Percentage factor, $1000=$ Conversion factor from gram to milligram, $20=$ Integral volume of digest analyzed or distilled, $0.1=$ Weight of sample in gram digested

$$
\% \text { Crude protein }=\% \text { nitrogen } \times 6.25
$$

Determination of carbohydrate (Clegg Anthrone method): Plant samples weighing $1 \mathrm{~g}$ were put into a $250 \mathrm{ml}$ volumetric flask. Distilled water $(10 \mathrm{ml})$ and $13 \mathrm{ml}$ of $62 \%$ perchloric acid was added and the mixture was shaken in order for it to homogenize completely. The flask was made up to $250 \mathrm{ml}$ with distilled water; the solution formed was filtered through a glass filter paper. Filtrate $(10 \mathrm{ml})$ was collected and transferred into a $100 \mathrm{ml}$ test tube; this was also diluted to volume with distilled water. The hydrolyzed solution was pipetted into a clean test tube and $5 \mathrm{ml}$ of Anthrone reagent was added, they were then mixed together. The whole mixture was read at $630 \mathrm{~nm}$ wavelength using the $1 \mathrm{ml}$ distilled water and the $5 \mathrm{ml}$ anthrone prepared as blank. Glucose solution of $0.1 \mathrm{ml}$ was also prepared and this was treated with the anthrone reagent. Absorbance of the standard glucose was calculated using the formula below:

$$
\begin{aligned}
& \% \mathrm{CHO} \\
& =\frac{25 \times \text { Absorbance of sample }}{(\text { Absorbance of glucose) } \mathrm{x} 1 \mathrm{~g} \text { of sample used }}
\end{aligned}
$$

Determination of moisture using the air oven method: Samples weighing $1 \mathrm{~g}$ were placed in a clean dry porcelain evaporation dish. This was placed in an oven to maintain a temperature of $105^{\circ} \mathrm{C}$ for six hours. The evaporating dish was cooled to room temperature in a desiccator and re-weighed to calculatethe moisture content (MC).

$$
\% \mathrm{MC}=\frac{\text { weight of fresh sample }- \text { weight of dried sample }}{\text { weight of sample use }} \times 100
$$

Determination of lipid by soxhlet extraction method: Samples weighing $2 \mathrm{~g}$ was inserted into a filter paper and placed into the soxhlet extractor. The extractor was fitted into a pre-weighed round bottomed dry distillation flask and the solvent acetone was added into it through the condenser. The extractor and the flask were held in place with a retort stand clamp. Cold water was passed into the condenser via the rubber tubing and the flask was heated such that the solvent refluxed continuously within the enclosure. The lipid in the solvent chamber was extracted through this process of continuous refluxing. After the lipid had been extracted completely from the sample, the condenser and the extractor were disconnected, the acetone solvent was distilled off and the lipid concentrate was cooled in the oven and re-weighed.

$$
\% \text { Lipid }=\frac{\text { weight of flask and extract }- \text { weight of empty flask }}{\text { weight of sample extracted }} \times 100
$$

Determination of ash by furnace method: The dried sample weighing $1 \mathrm{~g}$ was placed into a porcelain crucible which had been preheated and weighed. The crucible was inserted into a muffle furnace and regulated to a temperature $630^{\circ} \mathrm{C}$. After three hours it 
was removed from the furnace and allowed to cool to room temperature, and then it was re-weighed.

Determination of fibre: The fibre content was determined by difference. The other five proximate components were summed and the value gotten was subtracted from $100 \%$ giving the fibre content (100 per cent estimated proximate components represented the per cent fibre in the sample).

Determination of Amino acids using waters 616/626 LC (HPLC) Instrument: The sample preparation and determination were carried out in the following four stages: Hydrolysis: The samples $(0.5 \mathrm{~g})$ were weighed into a sterile furnaces hydrolysis tube $5 \mathrm{nmols}$ Norleucine was added to the samples and then dried under a vacuum. The tube was again placed in a vial containing $10.05 \mathrm{~N} \mathrm{HCl}$ with a small quantity of phenol, thereby hydrolyzing the protein by the $\mathrm{HCl}$ vapours under vacuum. This stage of hydrolysis of the sample lasted for between $20-23$ hours at $108^{\circ} \mathrm{C}$. After the hydrolysis, the samples were dissolved in ultra-pure water grade, containing ethylene diamine tetraacetic acid (EDTA). The EDTA chelates the metal was present in the samples. The hydrolysed samples now are stored in HPLC amino acid analyzer bottles for further analytical operations.

Derivatisation: The hydrolysed samples were derivalised automatically on the water 616/626 HPLC by reacting the five amino acid, under basic situations with phenylisothiocyanate (PITC) to get phenylthiocarbamyl (PTC) amino acid derivatives. The duration for this is 45 minutes per sample, as calibrated on the instrument. A set of standard solutions of the amino acids were prepared from Pierce Reference standards H (1000 $\mu \mathrm{mol})$ into autosampler crops and they were also derivatised. These standards $(0.0,0.5,1.0,1.5,2.0 \mu \mathrm{mol})$ were used to generate a calibration file that was used to determine the amino acids contents of the samples. After the derivatisation, a methanol solution $(1.5 \mathrm{~N})$ containing the PTC-amino acids was transferred to a narrow bore waters 616/626 HPLC system for separation.

HPLC separation and Quantization: The separation and quantization of the PTC-amino acids were done on a reverse phase (18 silica column) and the PTC chromophone were automatically and digitally detected at the wavelength of $254 \mathrm{~nm}$. The elution of the whole amino acids in the samples took 30 minutes. The buffer system used for separation was $140 \mathrm{~mm}$ sodium acetate $\mathrm{pH} 5.50$ as buffer A and 80\% acetonitrile as buffer $\mathrm{B}$. The program was ran using a gradient of buffer $\mathrm{A}$ and buffer $\mathrm{B}$ concentration and ending with a $55 \%$ buffer B concentration at the end of the gradient.

Data processing / interpretation and calculation: The intensity of the chromatographic peaks areas were automatically and digitally identified and quantified using a Dionex chromeleon data analysis system which is attached to the waters 616/626 HPLC System. The calibration curve or file prepared from the average values of the retention times (in minutes) and areas (in $\mathrm{Au}$ ) at the amino acids in 5 standards runs was used.

Since a known amount of each amino acid in the standard loaded into the HPLC, a response factor $(\mathrm{Au} / \mathrm{pmol})$ was calculated by the software that was interphased with the HPLC. This response factor was used to calculate the amount of each of the amino acid (in pmols) in the sample and displayed on the system digitally. The amount of each amino acid in the sample is finally calculated by the software by dividing the intensity of the peak area of each (corrected for the differing molar absorptivity's of the various amino acids) by the internal standard (Pierce) in the chromatogram and multiplying this by the total amount of internal standard added to the original sample.

After the picomole by the intensity of the height of each amino acid has been ascertained by the software, the data, the digital chromatographic software extrapolate back to 5 nmoles of the internal standard (Norleucine), and displays for the total amount that was pipetted into the hydrolysis tube at the beginning of the analysis as below:

$$
\begin{aligned}
& \mathrm{mg} / \mathrm{mL}(\text { in extract })=\text { dilution factor } \times \text { Peak height intensity } \\
& \mathrm{mg} / \mathrm{mL}(\text { in sample })=\frac{\mu g / m L \text { in extract } x \text { sample volume }}{\text { weight of sample }}
\end{aligned}
$$

\section{RESULTS AND DISCUSSION:}

Vitamins: The vitamin content of $T$. occidentalis grown in hydroponic medium (HM) and geoponic medium (GM) are presented in Table 1. It shows that cobalamin content was found high (40.29\%) followed by beta-carotene (19.89\%), riboflavin (13.25\%), ascorbic acid (10.33\%), thiamine $(9.78 \%)$, pyridoxine $(6.13 \%)$, niacin $(3.46 \%)$, tocopherols $(2.66 \%)$ and Vitamin K $(1.46 \%)$ in that order for HM while sequence for GM was beta-carotene $(17.27 \%)$, cobalamin $(12.70 \%)$, thiamine $(6.13 \%)$, ascorbic acid $(3.16 \%)$, pyridoxine $(2.12 \%)$, niacin $(1.25 \%)$, tocopherols $(0.97 \%)$, riboflavin $(0.80 \%)$ and Vitamin $\mathrm{K}(0.63 \%)$. The results revealed a higher percentage of vitamin in T. occidentalis grown in HM than GM. This also suggest that vitamin composition of plants vary depending on the substrate used for growth. 
Vitamin $\mathrm{K}$ value $(1.46 \% \mathrm{HM}, 0.63 \% \mathrm{GM})$ was the least among the vitamins assessed. This is within the daily recommended quantity of $80 \mu \mathrm{g}$ per day (Sami et al., 2014). The percentage composition of watersoluble and fat-soluble vitamins in $T$. occidentalis were $83.24 \%$ and $24.01 \%$ for HM and $26.16 \%$ and $18.87 \%$ for GM, respectively. According to Sami et al. (2014), daily requirement of vitamins are 15-20 $\mathrm{mg}$ for $\mathrm{B}_{3}, 2-3 \mathrm{mg}$ for $\mathrm{B}_{6}, 2.4 \mathrm{mg}$ for $\mathrm{B}_{12}, 60 \mathrm{mg} \mathrm{C}, 8$ $10 \mathrm{mg}$ for $\mathrm{E}, 0.08 \mathrm{mg}$ for $\mathrm{D}_{3}, 0.8-1 \mathrm{mg}$ for $\mathrm{A}, 2-7 \mathrm{mg}$ for $\beta$-carotene and $80 \mu \mathrm{g}$ for $\mathrm{K}_{3}$. The values obtained for individual vitamins were lower than the daily requirement of an adult. These vitamins are crucial in the functioning of human system. According to the Singh et al. (2012), vitamin C is a major antioxidant in the human body and possess the capacity to participate in enzymatic and hydroxylation reactions, participates in the oxidation-reduction processes. It also promotes the absorption of microelements such as iron and copper, involves in trace element metabolism and protects cells from damage caused by free radicals and environmental pollution.

Table 1: Percentage vitamins present in T. occidentalis grown in hydroponic and geoponic medium.

\begin{tabular}{|c|c|c|c|}
\hline \multirow{2}{*}{$\begin{array}{l}\text { Types of } \\
\text { vitamins }\end{array}$} & \multirow[t]{2}{*}{ Vitamins $(\%)$} & \multicolumn{2}{|c|}{ Growth medium } \\
\hline & & HM & GM \\
\hline \multirow[t]{6}{*}{ Water-soluble } & Vitamin $\mathrm{B}_{1}$ (thiamine) & 9.78 & 6.13 \\
\hline & Vitamin $B_{2}$ (riboflavin) & 13.25 & 0.80 \\
\hline & Vitamin $\mathrm{B}_{3}$ (Niacin) & 3.46 & 1.25 \\
\hline & Vitamin $\mathrm{B}_{6}$ (pyridoxine) & 6.13 & 2.12 \\
\hline & Vitamin $\mathrm{B}_{12}$ (cobalamin) & 40.29 & 12.70 \\
\hline & Vitamin C (ascorbic acid) & 10.33 & 3.16 \\
\hline \multirow[t]{3}{*}{ Fat-soluble } & Vitamin A (beta-carotene) & 19.89 & 17.27 \\
\hline & Vitamin E (tocopherols) & 2.66 & 0.97 \\
\hline & Vitamin $\mathrm{K}$ & 1.46 & 0.63 \\
\hline
\end{tabular}

It was earlier reported that the long term feeding of $T$. occidentalis supplemented diet caused a significant increase in weight of animals which may be due to its rich nutrients content (Emeka and Obidoa, 2009). Beta-carotene is a micronutrient essential to most mammalian species. It is necessary in vision, growth and development, gene transcription, immunity, dermatology (Combs, 2008; Duster, 2008; Nelson, et al., 2008). Many bioactive components such as vitamin $\mathrm{C}$ and $\mathrm{E}$, carotenoids, phenolic and thiol compunds have been reported to have natural protective effects against many illnesses. Vitamin C obtained for fresh T. occidentalis by Aminu et al. (2012) and Lawal et al. (2015) were lower when compared to this work. The amino acid composition and the vitamin profile of edible plants have been reported to be influenced by the fertility of the soil or the water in which they are growing (Atanasova, 2008). However, the metal ion composition is often more responsive (Chibuike and Obiora, 2014).

Proximate composition: Table 2 shows the proximate composition of $T$. occidentalis leaf grown in hydroponic medium and conventional geoponic medium. The moisture content was high $(83.36 \%$ HM, $81.42 \%$ GM). This is similar to other observations reported for T. occidentalis $86 \%$ (Kajihausa et al., 2010), T. occidentalis 86\%, T. triangulare $87.8 \%$, C. argentium $76.8 \%$ (Abidemi et al., 2009) and A. hybridus $84 \%, C$. argentina $71 \%, T$. triangulare $81 \%$, and $C$. acoitofolus $81 \%$ in the literatures (FAO, 1990). Carbohydrate content $(12.76 \%)$ was high when compared to earlier report on T. occidentalis $4.88 \%$ (FAO, 1990). The percentage of high percentage of carbohydrate is because carbohydrate make up a major class of natural organic compounds that are important for the maintenance of plant and animal life (Okonwu and Ariaga, 2016). Ash content of T. occidentalis were $0.37 \% \mathrm{HM}$ and $0.47 \% \mathrm{GM}$, while crude fibre and crude fat content were $(2.09 \% \mathrm{HM}$ and $4.76 \% \mathrm{GM})$ and $(0.90 \% \mathrm{HM}$ and $0.30 \% \mathrm{GM})$, respectively. Muhammad et al. (2015) suggested that the ash content of a plant is a function of its nutritionally important minerals.

The crude fat obtained from the result was low which agrees with Banerjee et al. (2012), which reported that vegetables contains low amounts of fat and calories. These fatty acids in vegetables are known to increase membrane fluidity and allow for osmosis intracellular and extracellular gaseous exchange (Lovejoy, 2002). Fibre cleanses the digestive tract by removing potential carcinogens from the body and prevents the absorption of excess cholesterol (Mensah et al., 2008). Fibres also add bulk to the food and prevent the intake of excess starchy food and may therefore guard against metabolic conditions such as hypercholemia and diabetes mellitus (Mensah et al., 2008). The proximate results are within permissible limits referenced to the potential of leafy vegetable in Nigeria.

Table 2: Proximate composition of $T$. occidentalis grown in hydroponic and geoponic medium.

\begin{tabular}{lll}
\hline & \multicolumn{2}{c}{ Growth medium } \\
\cline { 2 - 3 } Proximate (\%) & HM & GM \\
\hline Ash & 0.37 & 0.47 \\
Carbohydrate & 12.76 & 12.76 \\
Crude fibre & 2.09 & 4.76 \\
Crude fat & 0.90 & 0.30 \\
Moisture & 83.36 & 81.42 \\
Protein & 0.53 & 0.30 \\
\hline HM represents & Hydroponic medium; GM represents geoponic \\
medium
\end{tabular}


Amino acids: The amino acid profiles of $T$. occidentalis grown in hydroponic and geoponic medium using HPLC are listed in Table 3. This method identified and quantified twenty amino acids in $T$. occidentalis. The essential and non-essential amino acids ranges from $0.11-3.44 \%$ and $0.01-2.51 \%$ for $\mathrm{HM}$ and $0.05-1.73 \%$ and $0.01-1.26 \%$ for $\mathrm{GM}$, respectively. It is interesting to note that histidine, cysteine and threonine acids were the most concentrated amino acids for $T$. occidentalis grown in $\mathrm{HM}$ and GM, respectively. It was earlier reported that glutamic acid and aspartic acid were the most concentrated amino acids in $I$. gabonensis, $C$. maxima, A. viridis, B. alba, A. hybridus, $V$. amygydalina, $T$. occidentalis and $T$. triangulare (Adeyeye and Kenni, 2011; Adesina and Adeyeye, 2013; Omoyeni et al., 2015; Arowora et al., 2017). In their separate observations, the values obtained were different even though glutamine and aspartate were the most concentrated amino acids. This observation has shown that the concentration and presence of amino acids vary from one plant to another. The medium of propagation of plant is also a key factor to the concentration of amino acids. The percentage total amino acids for $\mathrm{HM}$ and GM were $19.07 \%$ and $9.77 \%$, respectively. This is an indication that $T$. occidentalis grown in hydroponic medium produced a higher concentration of amino acids as against the long practiced or conventional geoponic medium. The presents of 18 amino acids in T. occidentalis which are alanine, aspartic acid, glycine, glutamic acid, histidine, lysine, methionine, tryptophan, cysteine, leucine, arginine, serine, threonine, phenylalanine, valine, tyrosine, proline and isoleucine were earlier reported (Omoyeni et al., 2015; Arowora et al., 2017). However, this study revealed 20 amino acids in $T$. occidentalis with the inclusion of asparagine and glutamine. The percentage amino acids present in the leaf of $T$. occidentalis grown in HM were higher than in GM. Cuin and Shabala (2007) reported that amino acid concentration of plants increased in salt-stressed environment. Secondary metabolites such as alkaloid provide chemical defense for plants and amino acids are important in protein synthesis and precursors in the formation of secondary metabolism molecules (Croteau et al., 2000; Perez-Urria and Avalos-García, 2009). Aspartic acid function is essential for purine, pyrimidine, asparagine and inositol synthesis. Glutamic acid and glycine participate in the synthesis of glutathione increasing the antioxidant capacity of the plant. Valine maintains the balance of branched chain amino acids, whereas alanine is involved on hepatic autophagy, gluconeogenesis and transamination. Leucine regulates the protein turnover (mTOR signaling) and gene expression (Wu, 2009; Akram et al., 2011). Glycine, lysine, threonine and glutamate help to maintain intestinal integrity and health (Rhoads and Wu, 2009; Wang et al., 2009).

Table 3: Amino acid composition of the leaves of T. occidentalis grown in hydroponic and geoponic medium.

\begin{tabular}{|c|c|c|c|c|}
\hline \multirow[t]{2}{*}{ Types of amino acids } & \multirow[t]{2}{*}{ Amino acids (g/100g) } & \multicolumn{2}{|c|}{ Growth medium } & \multirow[t]{2}{*}{ *FAO (g/100gcp) } \\
\hline & & HM & GM & \\
\hline \multirow{9}{*}{ Essential } & Histidine & 3.44 & 1.73 & \\
\hline & Isoleucine & 1.23 & 0.62 & 4.20 \\
\hline & Leucine & 0.44 & 0.22 & 4.20 \\
\hline & Lysine & 1.75 & 0.92 & 4.20 \\
\hline & Methionine & 0.75 & 0.52 & 2.20 \\
\hline & Phenylalamine & 0.98 & 0.49 & 2.80 \\
\hline & Threonine & 2.46 & 1.23 & 2.80 \\
\hline & Tryptophan & 0.11 & 0.05 & \\
\hline & Valine & 0.14 & 0.07 & 4.20 \\
\hline \multirow[t]{11}{*}{ Non-essential } & Alanine & 1.02 & 0.51 & \\
\hline & Arginine & 0.86 & 0.43 & \\
\hline & Asparagine & 0.54 & 0.27 & \\
\hline & Aspartic acid & 0.38 & 0.19 & \\
\hline & Cysteine & 2.51 & 1.26 & 2.00 \\
\hline & Glutamic acid & 0.28 & 0.14 & \\
\hline & Glutamine & 1.40 & 0.70 & \\
\hline & Glycine & 0.36 & 0.18 & \\
\hline & Proline & 0.01 & 0.01 & \\
\hline & Serine & 0.09 & 0.05 & \\
\hline & Tyrosine & 0.31 & 0.16 & 2.80 \\
\hline Total amino acid & & 19.07 & 9.77 & \\
\hline
\end{tabular}

*Source: FAO, 1970; HM represents Hydroponic medium; GM represents geoponic medium

Conclusion: Telfairia occidentalis is rich with several health promoting compounds such as vitamins, amino acids and nutritional components. These bioactive compounds when grown hydroponically were found

Okonwu, K; Akonye, LA; Mensah, SI 
to be comparable to those grown in the soil (geoponic medium). The amount or concentrations of the bioactive compounds of plants grown by geoponic means are affected by several factors such as soil status and weather conditions. However, cultivation of $T$. occidentalis via hydroponic provides a better control on the quality of the bioactive compounds and crop yield through a complete control on the nutrient supply. This method (hydroponic) of cultivating vegetables will ensure the availability of vegetables all year round, especially in developing countries and help in addressing the challenges of food security, which is a global topical issue.

\section{REFERENCES}

Abidemi, TA; Adebayo, OJ; Idowu, O; Agbotoba, MO (2009). Nutrient content and antinutritional factors in Shea butter (Butryospermum parkii) leaves. Afr. J. Biotechnol. 8(21): 5888-5890.

Adesina, AJ; Adeyeye, EI (2013). Amino acid profile of three non-conventional leafy vegetables: $C$. maxima, Amaranthus viridis and Basella alba consumed in Ekiti State, Nigeria. IJAPS, 3 (1): 110.

Adeyeye, EI; Kenni, AM (2011). The comparative evaluation of amino acids profiles of the dehulled and hull parts of Irvingia gabonensis seeds. Biosci. Biotechnol. Res. Asia. 8 (2): 529-537.

Akram, M; Asif, H; Uzair, M; Akhtar, N; Madni, A; Shah, SMA; ul Hasan, Z; Ullah, A (2011). Amino acids: A review article. J. Med. Plants Res., 5: 3997-4000.

Aminu, M; Bello, MS; Abba, O; Aliyu, M; Malam, BS; Auwalu, G; Hafsat, AM; Shafi'u, M; Hussaina, NN; Hasiya, A; Sani, A (2012). Comparative in vitro Antioxidant Studies of Ethanolic extracts of Psidium guajava Stem Bark and Telfairia occidentalis Leaf. Inter. J. Modern Biochem. 1(1): 18-26.

Antonious, G; Lobel, L; Kochhar, T; Berke, T; Jarret, $\mathrm{R}$ (2009). Antioxidants in $C$. chinense: Variation among Countries Origin. J. Environ. Sci. Health. Part B, 44 (6): 621-666.

Arowora, KA; Ezeonu, CS; Imo, C; Nkaa, CG (2017). Protein Levels and Amino Acids Composition in Some Leaf Vegetables Sold at Wukari in Taraba State, Nigeria. Inter. J. Biol. Sci. Applicate. 4(2): 19-24.
Atanasova, E (2008). Effect of nitrogen sources on the nitrogenous forms and accumulation of amino acid in head cabbage. Plant Soil Environ. 54: 66-71.

Banerjee A; Datta, JK; Mondal, NK (2012). Biochemical changes in leaves of mustard under the influence of different fertilizers and cycocel.

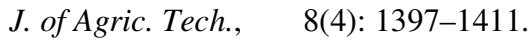

Bruijnzeel, LA; Scatena, FN; Hamilton, LS (2010). Tropical montane cloud forest. Science for conservation and management. Cambridge, Cambridge University Press, p. 137.

Chibuike, GU; Obiora SC (2014). Heavy metal polluted soils: effect on plants and bioremediation methods. Appl. Environ. Soil Sci.

Combs, GF (2008). The vitamins, Fundamental aspects in nutrition and health. 3rd ed. Elsevier Academic Press Burlington

Croteau, R; Kutchan, TM; Lewis, NG (2000). Natural products (secondary metabolites). Biochemistry and molecular biology of plants, pp. 1250-1318.

Cuin, TA; Shabala, S (2007). Amino acids regulate salinity induced potassium efflux in barley root epidermis. Planta, 225: 753-761.

Duster, G (2008). Retinoic acid synthesis and signalling during organogenesis. Cell, 134(6): 921-93.

Egedigwe, CA (2010). Effect of dietary incorporation of Vernonia amygdalina and Vernonia colorata on blood lipid profile and relative organ weights in albino rats (Thesis). Department of Biochemistry. MOUAU, Nigeria.

Emeka, EJI; Obidoa, O (2009). Some biochemical, haematological and histological responses to a long term consumption of Telfairia occidentalis supplemented diet in rats.

Pak. J. Nutri. 8: 1199-1203.

FAO (1970). Amino Acid content of foods and Biological Data on Proteins, Food and Agricultural Organization of the United Nations, Rome, Italy p. 285.

Funke, OM (2011). Food and Nutrition Sciences, 2: 249-252. 
Gosslau, A; Chen, KY (2004). Nuetraceuticals, apoptis and disease prevention. Nutri. 20: 95102.

Gupta, S; Lakshmi, J; Prakash, J (2008). Natural Product radiance 2: 111-116.

Kajihausa, OE; Sobukola, OP; Idowu, MA; Awonorin, SO (2010). Nutrient contents and thermal degradation of vitamins in organically grown fluted pumpkin (Telfairia occidentalis) leaves. Inter. Food Res. J. 17: 795807.

Kokwaro, J (2009). Medicinal plants of East Africa. 3rd ed. Nairobi, Kenya. University of Nairobi Press.

Lawal, OO; Essien, NC; Essien, NM; Ochalla, F (2015). Vitamin C content of some processed green leafy vegetables. European J. Expt. Biol. 5(2): 110-112.

Lee, Y; Lee, HJ; Lee, HS; Jang, YA; Kim, C (2008). Analytical dietary fiber database for the National Health and Nutrition Survey in Korea. J Food Compos Anal, 21: 35-42.

Lovejoy, JC (2002). The influence of dietary fats in insulin resistance current diabetes reports. 2 (5): 430-440.

Lubdha, K; Anjali, S (2014): Nutritional composition and Antioxidant Potential of Coastal, wild leafy vegetables from Ratnagiri district of Maharashtra. World J. Pharm. Pharmaceut. Sci. 3 (10): 890-897.

Mensah, JK; Okoli, RI; Ohaju-Obodo, JO; Eifediyi, K (2008). Phytochemical, nutritional and medicinal properties of some leafy vegetables consumed by Edo people in Nigeria. Afr. J. Biotechnol. 7(14): 2304-2309.
Muhammad, S; Umar, KJ; Sani, NA (2015). Evaluation of nutritional and anti-nutritional profiles of Ginger bread plum (Neocarya macrophylla) seed kernel from Sokoto Nigeria. Inter. J. Sci. Technol. 4: 361-367.

Nelson, A; Jenkins, O; Merran, P (2008). Neutrophil gelatinase associated lipocasin mediated Bcis retinoic acid-induced apoptosis of human sebaceous gland cells. $J$. Clinical Investigation, 118(8): 1468-1472.

Okonwu, K; Ariaga, CA (2016). Nutritional evaluation of various parts of Canna indica L. Annual Res. Review Biol. 11 (4): 1-5.

Omoyeni, OA; Olaofe, O; Akinyeye, RO (2015). Amino acid composition of ten commonly eaten indigenous leafy vegetables of South-West Nigeria. World J. Nutri. Health. 3(1): 16-21.

Rhoads, MJ; Wu, G (2009). Glutamine, arginine, and leucine signaling in the intestine. Amino Acids, 37: 111-122.

Sami, R; Li, Y; Qi, B; Wang, S; Zhang, Q; Han, F; Ma, Y; Jing, J; Jiang, L (2014). HPLC analysis of water-soluble vitamins (B2, B3, B6, B12 and C) and fat-soluble vitamins (E, K, D, A and $\beta$ Carotene) of Okra (A. esculentus). J. Chem. 1-6.

Singh, DP; Beloy, J; McInerney, JK; Day, L (2012). Impact of boron, calcium and genetic factors on vitamin C, carotenoids, phenolic acids, anthocyanins and antioxidant capacity of carrots. Food Chem. 132: 1161-1170.

Wang, W; Qiao, S; Li, D (2009). Amino acids and gut function. Amino Acids, 37: 105-110.

Wu, G (2009). Amino acids: metabolism, functions, and nutrition. Amino Acids, 37: 1-17. 